\title{
LIV. A method of correcting the variation of the mariner's compass
}

\section{Mr. John Hodgson}

To cite this article: Mr. John Hodgson (1812) LIV. A method of correcting the variation of the mariner's compass, Philosophical Magazine Series 1, 39:169, 370-373, DOI: $10.1080 / 14786441208638145$

To link to this article: http://dx.doi.org/10.1080/14786441208638145

册 Published online: 27 Jul 2009.

Submit your article to this journal

Џ Article views: 2

Q View related articles $₫$ 
peared. Some may say, that in the present instance the deranged state of the skin and of the bowels was the effect of the disease, and that the treatment adopted removed the effect without first removing the cause: but this case (as well as many others) clearly proves to me the importance and great necessity of paying strict attention to the state of the skin, and of the alimentary canal, in every disease.

I am, with all due respect, Your humble servant,

Hatton Garden, May $16,18.12$. JOHN BURNE.

LIV. A Method af correeling the Variation of the Mariner's Compass. By Mr. Joun Hodgsan, Charles Street, St. James's Square*,

SIR, $I_{\text {TAKE }}$ the liberty of requesting you to submit to the Society for the Encouragement of Arts, Manufactures and Commerce, a small theodolite, to which an addition has been made, calculated, it is hoped, to be of some utility,

The frequent recurrence to the variation of the compass, which is necessary in the use of the theodolite, is always attended with trouble, and not unfrequently productive of error.

It appears to me, that by a very simple expedient these inconveniences may in a great measure be removed. To the magnetic needle of the instrument, let one of brass be affixed moveable upon the centre of the former; the brass needle may be termed the corrector. Nothing more is necessary than to place the magnetic needle and the eorrector, at the angle of the variation, in such a manner that, the former being in the magnetic meridian, the latter shall be in the true meridian. The south end of the corrector will point to the true bearing of an object seen through the sights of the theodolite.

I also beg to lay before the committee a ship's compass, in which will be found a different application of the same principle. In this instrument, the needle is made moveable under the compass card, so as to be placed by the officer of the watch, or any other proper person, under the variation line, as often as an azimuth or an amplitude shall have been taken. The points of the compass will, by these

* From Transactions of the Society for the Encouragement of Arts, Manufactures, and Commerce, for 1811 . The silver medal of the Socisty was voted to Mr. Hodgson for this communication. 
means, be directed to their corresponding points in the heavens, and the mariner will know that he is really sailing upon the rhumb indicated by the cord.

I am inclined to think that a seaman may sometines be liable to error, in the continual reference which it is necessary for him to make to the variation of the compass, from 2 possibility of his allowing it on the wrong side, by subtracting where he should add, or by adding where he should subtract it : even under a supposition that such a mistake is not likely to occur, the use of this instrument as an additional check, in a matter of so much importance as is the ascertaining of a ship's course, may not be entirely unworthy of attention.

It is very probable, that from my imperfect information upon these subjects, I am now proposing what has before been suggested, and been found either to be wholly im. practicable, or of little or no utility when reduced to practice, This is indeed the more probable from the extreme simplicity of the expedient itself, which could scarcely have escaped the attention of the many enlightened seamen, and others, who bave devoted their minds to subjects of this nature. This consideration, however, is not sufficient to induce me to lose a chance of suggesting any the most trifling hint which may be useful to a class of men to whom we are so much indebted.

It may be objected against the application of this principle to a ship's compass, that as the variation in a long voyage is continually changing, the card in a short time after it has been adjusted will not point truly. This must be admitted; but it must also be recollected that it will agree with the last variation ascertained, and which is that on which the mariner must rely, until a fresh observation shall have been taken.

It may also be objected, that through the negligence of the persons employed to regulate this instrument, errors may arise, equal to those which it is intended to obviate; but surely, whatever may tend to afford a correct knowledge of a ship's course, is of sufficient importance to render the adjustment of the card an office by no means unworthy of the captain himself; and it cannot be supposed that he, or indeed any other officer, can be liable to error in an operation merely manual.

If we admit, however, that these objections are well founded, an instrument of this description might not be destitute of utility, placed in the captain's cabin, or some other convenient part of the ship, where it might continu- 


\section{A Method to correct the Variation of the Compass.}

ally indicate her course, without the necessity of a reference to the last observation; and at the same time serve as a check upon the several courses entered from the steeringcompass,

Whatever obstacles may exist to the application of this contrivance to the ship's compass, I appreherid that there will be none to its utility, as applied to the instruments used in land surveying; confined as that business is to tracts of country within which only a trifling annual variation takes place, and to which variation the corrector may be set whenever it becomes considerable.

To the common boat- and pocket-compass the same principle may be applied with equal utility ; to the latter especially, which may frequently, perhaps, be in the hands of persons unacquainted with either the bearing or amount of the variation of the magnetic needle,

As the instruments submitted to the Committee are merely intended for illustration, I have not aimed at great nicety in their mechanism. It is obvious that they are capable of considerable improvement, and that both the theodolite and the ship's compass may be so constructed as to be capable of all requisite accuracy in their adjustment, without loading them in such a manner as to obstruce the free motion of the needle.

If a modification of these instruments, in itself sa simple, shall be found to be of the least utility, I shall feel highly gratified.

$$
\begin{aligned}
& \text { I am, sir, } \\
& \text { Your very obedient servant, } \\
& \text { JoHn HoDGson. } \\
& \begin{array}{l}
\text { Charles Street, St. James's Square, } \\
\text { April } 23,1811 \text {. }
\end{array}
\end{aligned}
$$

To C. Taylor, M.D. Sec.

\section{Reference to the Drawing of Mr. John Hodgson's Vari- ation Compass. Plate IX. fig. 1 and 2.}

The two figures in this plate are, a plan and perspective view of a small theodolite or circumferentor, for taking horizontal angles by the magnetic needle; it is to the latter alone that Mr. Hodgeon's improvement applies; being a brass needle $a$, fig. 1, which is fitted upon the brass centrepiece, or cap, of the real needle $b$, in such a manner that it can be easily turned round to make any angle with the needle, and having sufficient friction to remain where it is placed; both needles are poised on the same centre-point, with an agate cap in the usual manner, the brass needle 
Phil Mag.Til.XXXiX $1 \%$.

MrHodgson' Improved Compass.
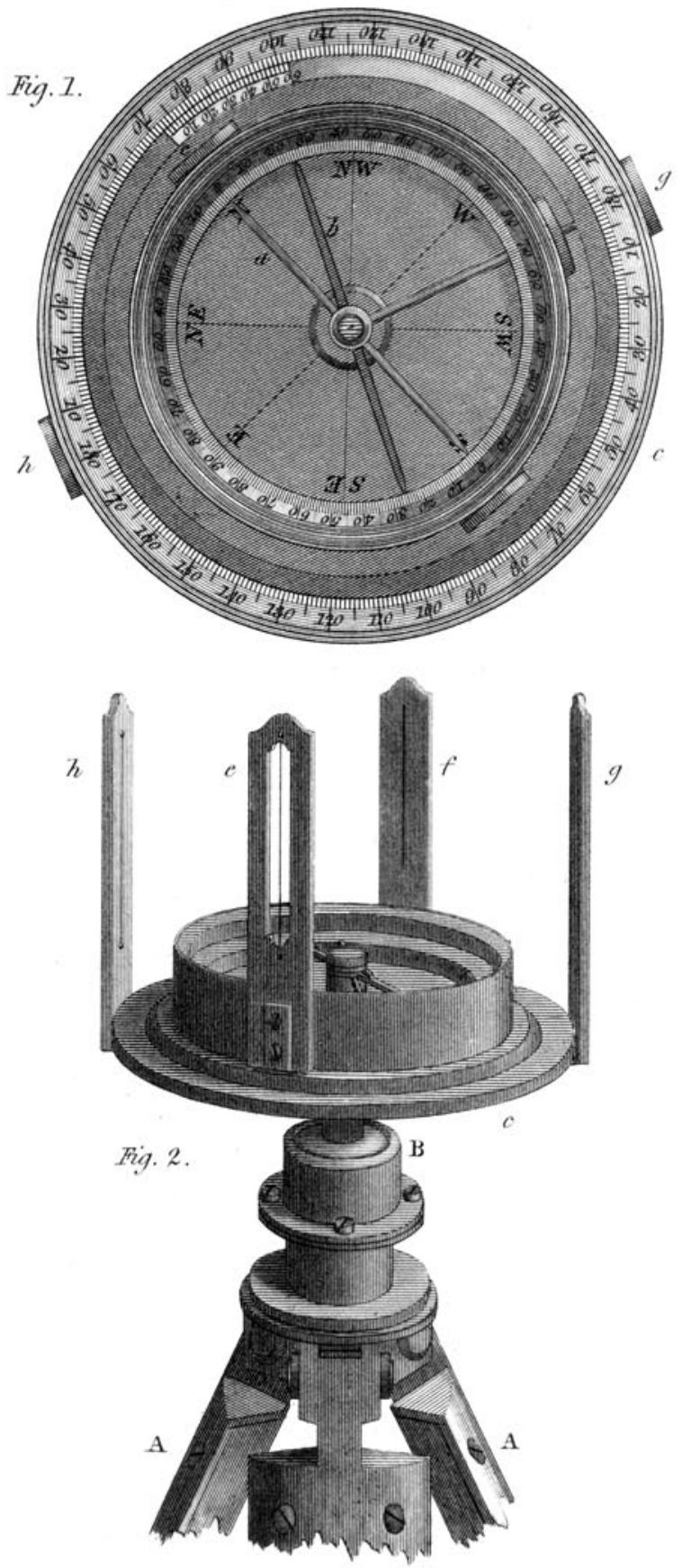
being only an index to point out the divisions on the circle within the compass : this index being set so as to make the same angle with the needle, as the difference of the true and magnetic meridians, will at all times give the true bearings of any object observed through the two sights $e$ and $f$, which are diametrically opposite, and at the zero of the divided circle; at least whilst the variation of the needle continues the same; but as this alters by the instrument being used in a different tract of country, the brass index $a$ must be turned round a corresponding number of degrees, which are shown by the divided circle in the box. The remaining parts, shown in fig. 2 , are AA, the upper ends of the tripod supporting the instrument; $B$ the ball and socket by which the box is adjusted, so as to be horizontal; the stem of the ball has a circle $c$ fixed to it, carrying two sights $g h$, through which the observations are taken; the circle $c$ is divided into degrees, and the compass-box, which turns round upos it, has a vernier applying to them : this renders the instrument a theodolite, as any two objects may be observed through the sights $e f$, and $g h$, and the divisions on the circle $c$ will denote the angle between them, and at the same time the bearing of any object may be taken by observing it through the sights $e f$, and noting the degree pointed out by the brass needle $a$, which is the true bearing required, without any allowance for the variation, as was the case in the common instrument.

I.V. On the Rev. Mr. Liston's Euharmonic Organ, and his "Essay on perfect Intonation," just published, for explaining fully the Principles of Tuning, and of performing upon this Organ with perfect Harmonies, in almost every possible Variety of Keys and Passages. By Mr. John Farey Sen.

\section{To Mr. Tilloch.}

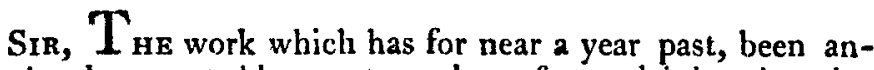
xiously expected by great numbers, for explaining the principles and practice of a Musical Scale, without any temperament or imperfections in its harmony, has at length appeared and is to be had of Messrs. Longman and Rees, or any other Bookseller, or at the Music-seliers, and I take the earliest opportunity, of mentioning a few particulars therefrom, in addition to what I communicated in your 